\title{
Biochemical Methanol Gas Sensor (MeOH Bio-Sniffer) for Non-Invasive Assessment of Intestinal Flora from Breath Methanol
}

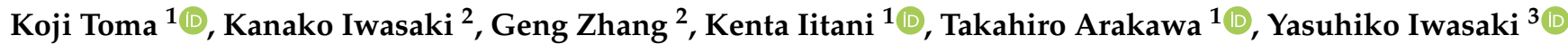 \\ and Kohji Mitsubayashi ${ }^{1,2, *}$
}

1 Department of Biomedical Devices and Instrumentation, Institute of Biomaterials and Bioengineering, Tokyo Medical and Dental University (TMDU), 2-3-10 Kanda-Surugadai, Chiyoda-ku,

Tokyo 101-0062, Japan; toma.bdi@tmd.ac.jp (K.T.); i.bdi@tmd.ac.jp (K.I.); arakawa.bdi@tmd.ac.jp (T.A.)

2 Graduate School of Medical and Dental Sciences, Tokyo Medical and Dental University (TMDU), 1-5-45 Yushima, Bunkyo-ku, Tokyo 113-8510, Japan; ma170016@outlook.jp (K.I.); ma201102@tmd.ac.jp (G.Z.)

3 Faculty of Chemistry, Materials and Bioengineering, Kansai University, Osaka 564-8680, Japan; yasu.bmt@kansai-u.ac.jp

* Correspondence: m.bdi@tmd.ac.jp

\section{check for}

updates

Citation: Toma, K.; Iwasaki, K.; Zhang, G.; Iitani, K.; Arakawa, T.; Iwasaki, Y.; Mitsubayashi, K. Biochemical Methanol Gas Sensor (MeOH Bio-Sniffer) for Non-Invasive Assessment of Intestinal Flora from Breath Methanol. Sensors 2021, 21, 4897. https://doi.org/10.3390/ s21144897

Academic Editor: Roberto Pizzoferrato

Received: 17 June 2021

Accepted: 16 July 2021

Published: 19 July 2021

Publisher's Note: MDPI stays neutral with regard to jurisdictional claims in published maps and institutional affiliations.

Copyright: (c) 2021 by the authors. Licensee MDPI, Basel, Switzerland. This article is an open access article distributed under the terms and conditions of the Creative Commons Attribution (CC BY) license (https:/ / creativecommons.org/licenses/by/ $4.0 /)$.

\begin{abstract}
Methanol $(\mathrm{MeOH})$ in exhaled breath has potential for non-invasive assessment of intestinal flora. In this study, we have developed a biochemical gas sensor (bio-sniffer) for $\mathrm{MeOH}$ in the gas phase using fluorometry and a cascade reaction with two enzymes, alcohol oxidase (AOD) and formaldehyde dehydrogenase (FALDH). In the cascade reaction, oxidation of $\mathrm{MeOH}$ was initially catalyzed by AOD to produce formaldehyde, and then this formaldehyde was successively oxidized via FALDH catalysis together with reduction of oxidized form of $\beta$-nicotinamide adenine dinucleotide $\left(\mathrm{NAD}^{+}\right)$. As a result of the cascade reaction, reduced form of NAD (NADH) was produced, and $\mathrm{MeOH}$ vapor was measured by detecting autofluorescence of NADH. In the development of the $\mathrm{MeOH}$ bio-sniffer, three conditions were optimized: selecting a suitable FALDH for better discrimination of $\mathrm{MeOH}$ from ethanol in the cascade reaction; buffer $\mathrm{pH}$ that maximizes the cascade reaction; and materials and methods to prevent leaking of $\mathrm{NAD}^{+}$solution from an AOD-FALDH membrane. The dynamic range of the constructed MeOH bio-sniffer was $0.32-20 \mathrm{ppm}$, which encompassed the $\mathrm{MeOH}$ concentration in exhaled breath of healthy people. The measurement of exhaled breath of a healthy subject showed a similar sensorgram to the standard $\mathrm{MeOH}$ vapor. These results suggest that the $\mathrm{MeOH}$ bio-sniffer exploiting the cascade reaction will become a powerful tool for the non-invasive intestinal flora testing.
\end{abstract}

Keywords: intestinal flora; methanol; gas-phase biosensor; enzymatic cascade reaction; fluorescence

\section{Introduction}

Intestinal flora has been gaining its attention year by year after several reports were made regarding influences of the intestinal flora to general health conditions [1,2]. In particular, two dominant bacteria, the Bacteroidetes and the Firmicutes [3-6], play important roles as their composition in intestinal bacteria, and metabolites affect the host's immune function, obesity, drug metabolism, and absorption [7-9].

Currently, there are two main methodologies to assess the status of intestinal flora: culture method and genome analysis. In culture method, bacteria extracted from stool sample are cultured, and the resultant morphology and color tone of the colonies are observed [10,11]. This method is inexpensive, but one needs a long time to have results. Furthermore, it is unable to observe more than $90 \%$ of intestinal microorganisms because of lack of growth substrates and difficulties in maintaining the culture environment such as temperature, $\mathrm{pH}$, and osmotic pressure, which are varied for different bacteria [12]. For example, it is hard for obligatory anaerobic bacteria such as Bacteroidetes to survive 
and grow in healthy conditions if the stool sample is exposed in ambient air for a long time. Therefore, this method is suitable for detecting the presence of bacteria of interest in a stool sample that one can grow, but not for reflecting actual intestinal flora nor for quantitative assessment.

On the other hand, in genome analysis with next generation sequencing, it is possible to obtain nucleotide sequence information rapidly along with high-throughput without the culturing. This method identifies sequential information of $16 \mathrm{~S}$ ribosomal RNA (rRNA), which is amplified using polymerase chain reaction (PCR). The obtained sequential information allows phylogenetic classification and identification of bacteria. A report said $93 \%$ of $182216 \mathrm{~S}$ rRNA sequences from intestine bacteria that are detectable by the genome analysis cannot be identified by the cultured method [13]. The disadvantage of this method is the cost through molecular phylogenetic processes [14].

Methanol $(\mathrm{MeOH})$ is produced from the degradation of dietary fiber, pectin, and by intestinal bacteria, including Bacteroidetes [15-17]. This produced $\mathrm{MeOH}$ is transferred to the blood stream, and a fragment of the blood $\mathrm{MeOH}$ is released through exhaled breath. The study of Laakso et al. showed a good correlation of the $\mathrm{MeOH}$ concentration between exhaled breath and blood [18]. There are some reports demonstrating increase in $\mathrm{MeOH}$ concentration in exhaled breath after intaking pectin. For example, a study by Dorokhov et al. observed the increase of the blood $\mathrm{MeOH}$ concentration up to 1.5 times after eating vegetables [19]. According to a study by Lindinger et al., eating pectin-contained fruits, such as apples, lead to the increase in breath $\mathrm{MeOH}$ concentration [20]. These reports suggest the potential for non-invasive assessment of intestinal bacteria activity by measuring $\mathrm{MeOH}$ in exhaled breath.

$\mathrm{MeOH}$ in exhaled breath has been analyzed by various methodologies, such as gasliquid chromatography [21], proton-transfer-reaction mass spectrometry (PTR-MS) [20], and selected-ion flow-tube mass spectrometry (SIFT-MS) [22,23]. Despite their capability of identifying $\mathrm{MeOH}$ in gas mixture, the size and complexity of the system are drawbacks for the on-site $\mathrm{MeOH}$ assessment.

On the other hand, sensors are expected to be used closer to the site than lab-based analytical devices. Therefore, it is required that sensors be simple to operate and compact in size along with sufficient sensitivity, selectivity, and capability of continuous measurement for some occasions [24-29]. However, generally, there is a trade-off between being compact in size and having high sensitivity, and it is very challenging to meet both requirements. To overcome these challenges, a lot of efforts have been devoted to improving the sensitivity and selectivity of $\mathrm{MeOH}$ gas sensors. For example, Li et al. synthesized a Pt-SnO $\mathrm{O}_{2}$ nanoparticles composite for a chemoresistive gas sensor [30]. An alumina tube surface was coated with this nanocomposite to fabricate a sensor, and $\mathrm{MeOH}$ vapor was measured by changes in the resistance of the sensor. As a result, the sensor using $\mathrm{Pt}_{-} \mathrm{SnO}_{2}$ showed about 10-fold better sensor output to $100 \mathrm{ppm}$ methanol vapor at $120^{\circ} \mathrm{C}$ lower operating temperature than those with pristine $\mathrm{SnO}_{2}$ microspheres $\left(220^{\circ} \mathrm{C}\right)$. As an another $\mathrm{SnO}_{2}$-based chemoresistive gas sensor, $\mathrm{Chen}$ et al. developed a lanthanum-doped $\mathrm{SnO}_{2}$ nanocomposite. Similar to Li's study, the lanthanum-doped $\mathrm{SnO}_{2}$ nanocomposite was coated on a ceramic tube, and $\mathrm{MeOH}$ vapor was measured by changes in the resistance. The sensor output was improved by a factor of 7 with the lanthanum-doped $\mathrm{SnO}_{2}$ compared to the sensor with only $\mathrm{SnO}_{2}$ when measuring $75 \mathrm{ppm} \mathrm{MeOH}$ vapor at the operating temperature of $220{ }^{\circ} \mathrm{C}$ [31]. A $\mathrm{MeOH}$ gas sensor employing metal-organic framework was reported by Andrés et al. [32]. The sensor was fabricated by depositing MIL-96(Al) nanoparticles on a $\mathrm{Si} / \mathrm{SiO}_{2}$ substrate with interdigitated electrodes. It showed different sensor outputs to water and $\mathrm{MeOH}$ vapor from other VOCs, which will be useful to identify these two components out of gas mixture. There are also reports regarding handheld $\mathrm{MeOH}$ gas sensors for immediate use in the field $[18,33,34]$. Broek et al. introduced a $\mathrm{MeOH}$ sensor that was composed of a separation column and Pd-doped $\mathrm{SnO}_{2}$ chemoresistive sensor. This combination made the size compact and made it possible to measure $\mathrm{MeOH}$ vapor even in the presence of much higher concentration of ethanol within $2 \mathrm{~min}$ [33]. As another approach, recent advances in 
machine learning were applied to an electronic nose (e-nose) with a pattern recognition algorithm. Due to their high technological affinity, the e-nose using graphene FET was able to classify water, $\mathrm{MeOH}$, and ethanol with high accuracy [35].

Although there has been great advancement of such sensors, it is not yet easy to selectively measure $\mathrm{MeOH}$. Recently, we have developed a liquid phase biosensor for $\mathrm{MeOH}$ (the AOD-FALDH fluorosensor) that employed two-enzyme cascade reaction with alcohol oxidase (AOD), formaldehyde dehydrogenase (FALDH), and fluorometry [36]. The cascade reaction begins with oxidation of $\mathrm{MeOH}$ via AOD to produce formaldehyde, and then produced formaldehyde is oxidized via FALDH together with reduction of a coenzyme, which is an oxidized form of $\beta$-nicotinamide adenine dinucleotide $\left(\mathrm{NAD}^{+}\right)$. $\mathrm{MeOH}$ was measured by detecting autofluorescence from a reduced form of NAD (NADH). Due to the cascade reaction, the AOD-FALDH fluorosensor was able to measure $\mathrm{MeOH}$ with high selectivity, especially from other aliphatic alcohols, including ethanol. Based on these results, it is expected that the AOD-FALDH fluorescence is applicable to the non-invasive measurement of $\mathrm{MeOH}$ in such body fluids as urine or saliva, but it would be quicker and easier if the same assessment could be made with exhaled breath. As mentioned above, the measurement of gas phase samples is more challenging than liquid phase samples because gas phase samples are usually invisible and more rapidly diffuse. In particular, exhaled breath contains a considerable portion of water with the relative humidity of $65-91 \%$, according to the study by Mansour et al. [37]. Besides, the $\mathrm{MeOH}$ concentration in breath is approximately 3000-times lower than that in blood [18]. Therefore, a sensor for $\mathrm{MeOH}$ in exhaled breath needs to be highly sensitive to $\mathrm{MeOH}$ as well as insensitive to humidity. Our biochemical gas sensor (bio-sniffer) has shown those required characteristics in previous studies for ethanol, acetaldehyde, isopropanol, and acetone [38-41], and in this study, we combined the advantages of the bio-sniffer and AOD-FALDH cascade reaction to measure $\mathrm{MeOH}$ in exhaled breath.

\section{Materials and Methods}

\subsection{Materials and Reagents}

Alcohol oxidase (AOD, A2404-1KU, from Pichia pastoris) was obtained from SigmaAldrich Japan (Tokyo, Japan). Formaldehyde dehydrogenase (FALDH, from Pseudomonas sp.) was from two different manufacturers, Funakoshi (Tokyo, Japan) and Toyobo (Osaka, Japan). An oxidized form of $\beta$-nicotinamide adenine dinucleotide (NAD ${ }^{+}$) was purchased from Oriental Yeast (Tokyo, Japan). A hydrophilic polytetrafluoroethylene (H-PTFE) membrane (thickness: $80 \mu \mathrm{m}$, porosity: $80 \%$, pore size: $0.2 \mu \mathrm{m}$ ) was from Millipore (Burlington, MA, USA). Poly [2-methacryloyloxyethyl phosphorylcholine (MPC)co-2-ethylhexyl methacrylate (EHMA)] (PMEH) was synthesized in house by the free radical-polymerization method [42]. Polyethyleneimine (PEI, average molecular weight of 10,000, 164-17821) and glutaraldehyde (GA, 079-00533) were purchased from Fujifilm Wako Pure Chemical (Osaka, Japan).

All reagents for the following buffer solutions were obtained from Fujifilm Wako Pure Chemical (Osaka, Japan). For the phosphate buffer (PB, $100 \mathrm{mM}$ ) solution, we added potassium dihydrogen phosphate solution $(100 \mathrm{mM}$ in ultrapure water) to disodium hydrogen phosphate solution (100 $\mathrm{mM}$ in ultrapure water) to buffer the solution $\mathrm{pH}$ from 6.5 to 8.5 . For the Tris- $\mathrm{HCl}$ solution $(100 \mathrm{mM})$, we added $\mathrm{HCl}$ solution to $100 \mathrm{mM}$ trimethylolaminomethane solution to buffer the $\mathrm{pH}$ from 8.5 to 10.5 .

\subsection{Construction of $\mathrm{MeOH}$ Bio-Sniffer}

The MeOH bio-sniffer exploited a cascade reaction with AOD and FALDH that is described elsewhere (Figure 1a) [36]. The reaction begins with oxidation of MeOH via AOD catalysis, which produces formaldehyde. Then, oxidation of the produced formaldehyde occurs via FALDH in conjunction with the reduction of $\mathrm{NAD}^{+}$, in which formic acid and NADH are produced. We measured $\mathrm{MeOH}$ vapor indirectly by autofluorescence of $\mathrm{NADH}$, whose emission $\lambda_{\mathrm{em}}$ and excitation $\lambda_{\mathrm{ex}}$ wavelengths were $490 \mathrm{~nm}$ and $340 \mathrm{~nm}$, 
respectively. In this principle, the fluorescence intensity increased if the concentration of $\mathrm{MeOH}$ increased.

(a)

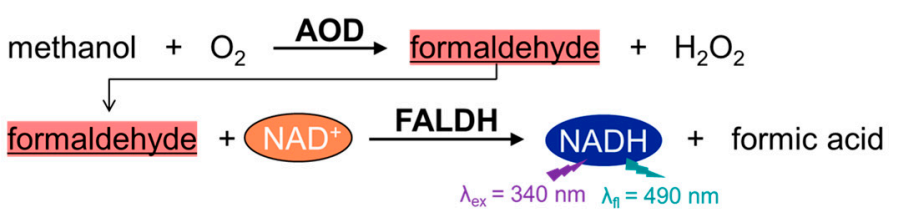

(b)

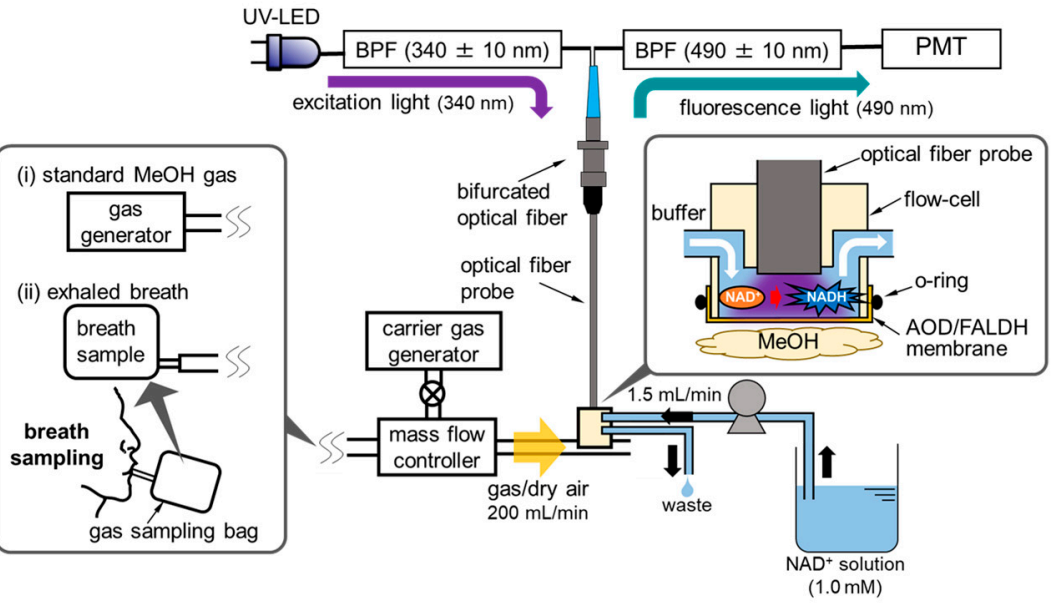

Figure 1. (a) Measurement principle, and (b) a schematic illustration of the MeOH bio-sniffer.

The device configuration of the $\mathrm{MeOH}$ bio-sniffer was similar to the ones in our previous studies except for the membrane $[39,43,44]$. Briefly, it consisted of a bifurcated optical fiber (PVSMA2-2 STU600-STUH190S, Mitsubishi Cable Industries, Tokyo, Japan), an optical fiber probe (F1000-900, Ocean Insight, Orlando, FL, USA), a UV light emitting diode (UV-LED, UF4LU-0GD01, DOWA, Tokyo, Japan), and a photomultiplier tube (PMT, C9692-11, Hamamatsu Photonics, Shizuoka, Japan). At the end of the optical fiber probe that was connected to the bifurcated optical fiber, a flow-cell made from poly methyl methacrylate was attached. An AOD-FALDH membrane was attached on the flow-cell and worked as a gas-liquid diaphragm (Figure $1 b$ ). In the flow-cell, $\mathrm{NAD}^{+}$solution flowed over the AOD-FALDH membrane at the flow rate of $1.5 \mathrm{~mL} / \mathrm{min}$ using a peristatic pump (MP-1000-H, Tokyo Rikakikai, Tokyo, Japan). When MeOH vapor reached and diffused into the membrane, the enzymatic reaction described in Figure 1a occurred, which resulted in producing NADH in the solution. The excitation UV light, which originated from the LED and traveled through the bifurcated optical fiber and the optical fiber probe, was irradiated to NADH in the solution, and then emitted fluorescence from NADH was collected by the optical fiber. After being filtered by a bandpass filter (BPF, $\lambda=490 \pm 5 \mathrm{~nm}$, Asahi Spectra, Tokyo, Japan), the fluorescence light was detected by the PMT.

\subsection{Preparation of AOD-FALDH Membrane}

First, waterproofing was made on the gas phase side of the membrane, which was opposite to the side of AOD and FALDH being immobilized, because the AOD-FALDH membrane was hydrophilic, and thus, the $\mathrm{NAD}^{+}$solution in the flow-cell had leaked into the gas phase (Figure 2). In order to avoid both sides of a H-PTFE membrane becoming hydrophobic, the H-PTFE membrane was moderately wetted with ultrapure water before the treatment. Then, a surface of the H-PTFE membrane was coated with a hydrophobic material. After the coating, the H-PTFE membrane was dried out, and the membrane being hydrophobic on onside and hydrophilic on the other side was obtained. In the waterproof treatment, three different materials, including PMEH, a fluorine resin (Amedas, Columbus, Tokyo, Japan), and a silicone resin (NeverWet, Lancaster, PA, USA), were compared. 


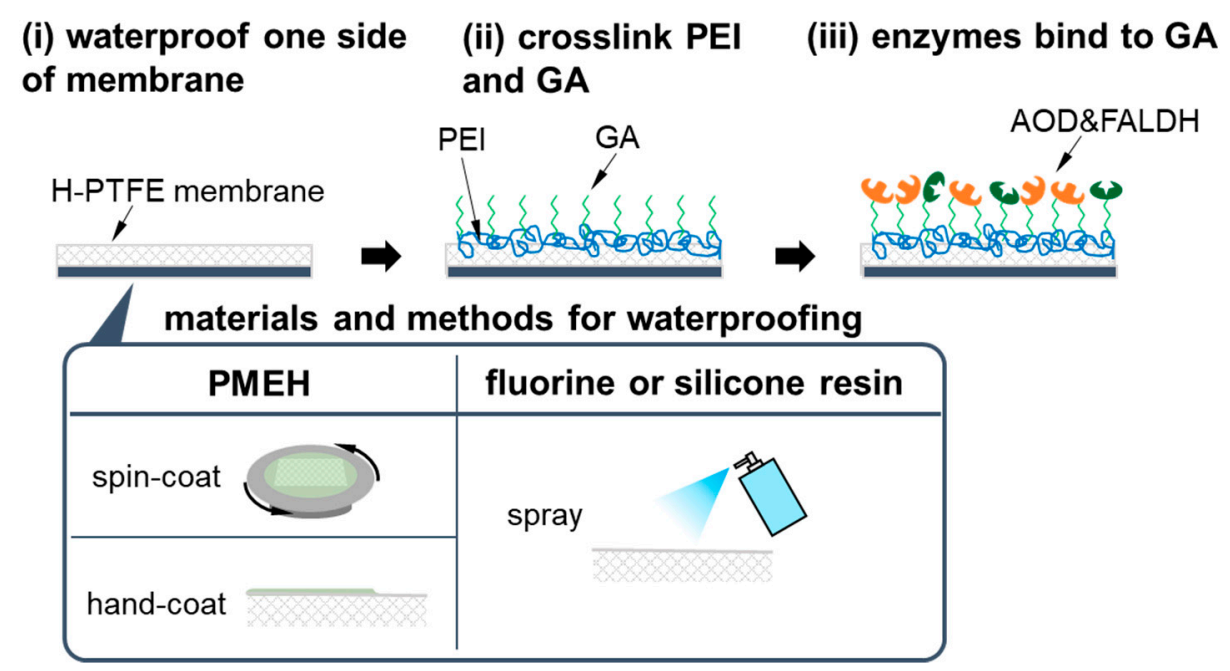

Figure 2. Preparation processes of the AOD-FALDH membrane.

PMEH was either spin-coated or hand-coated. In the case of spin-coating, a $2 \times 2 \mathrm{~cm}^{2}$ H-PTFE membrane wetted with ultrapure water was fixed on a silicon wafer, and then it was set on a spin-coater (1H-D7, Tokyo, Mikasa, Japan). After adding PMEH solution (10 $w / w \%$ in ethanol) dropwise to the H-PTFE membrane, it was spin-coated at spin rate of $4000 \mathrm{rpm}$. In the hand-coating, the PMEH solution applied to the H-PTFE membrane was spread out well by a hand. The coating with the fluorine resin or silicone resin was carried out by spraying a resin to a H-PTFE membrane for $5 \mathrm{~s}$ and drying it for $30 \mathrm{~min}$.

Next, AOD and FALDH were immobilized on this waterproofed H-PTFE membrane with the similar protocol that has been described in detail elsewhere [36]. AOD and FALDH were crosslinked to PEI using GA on the hydrophilic side of a H-PTFE membrane in the following procedures. We first dropped $300 \mu \mathrm{L}$ PEI solution $(1 w / w \%$ in PB) onto a $2 \times 2 \mathrm{~cm}^{2}$ H-PTFE membrane and gently shook it for $5 \mathrm{~min}$. Then, we rinsed excessive PEI from the membrane with $300 \mu \mathrm{L}$ PB for three times. Afterwards, we dropped $300 \mu \mathrm{L}$ GA solution $(2.5 v / v \%$ in $\mathrm{PB})$ to the membrane and gently shook it for $5 \mathrm{~min}$ to crosslink PEI and GA. After rinsing excessive GA from the membrane with PB for three times, a mixed solution of AOD $\left(2.0\right.$ unit $\left./ \mathrm{cm}^{2}\right)$ and FALDH $\left(1.0 \mathrm{unit} / \mathrm{cm}^{2}\right)$ was casted over the membrane and left for $15 \mathrm{~min}$ in a dark cold place $\left(4^{\circ} \mathrm{C}\right)$ to immobilize them. Finally, Tris- $\mathrm{HCl}$ solution was used to passivate the residual aldehyde group of GA, which would cause non-specific binding of NADH to GA.

\subsection{Measurement of Standard $\mathrm{MeOH}$ Vapor and Exhaled Breath $\mathrm{MeOH}$}

First, the developed $\mathrm{MeOH}$ bio-sniffer was characterized with standard $\mathrm{MeOH}$ vapor. The standard $\mathrm{MeOH}$ released from a gas generator (PD-1B-2, Gastec, Kanagawa, Japan) was pumped to the flow-cell of the bio-sniffer at the regulated flow rate of $200 \mathrm{~mL} / \mathrm{min}$ by a mass flow controller (FD-C1, Keyence, Osaka, Japan). The measurement began with acquiring the baseline of the fluorescence intensity from air cleaned through an active carbon filter (3001-17201, GL Sciences, Tokyo, Japan) and a silica gel filter (3001-17111, GL Sciences, Japan). This filtered air was also used as a carrier gas for $\mathrm{MeOH}$ vapor. Then, the gas line was switched to the gas generator, and $\mathrm{MeOH}$ vapor flowed to the bio-sniffer for $5 \mathrm{~min}$. Finally, the gas line was switched back to the filtered air to initialize the measurement.

After the series of characterizations, the bio-sniffer was applied to the measurement of $\mathrm{MeOH}$ in exhaled breath of a healthy subject. This experiment was approved by the ethics committee of Institute of Biomaterials and Bioengineering, Tokyo Medical and Dental University (approval number: B2014-001), and was performed in accordance with the guidelines and regulations after informed consent had been obtained from a subject. Exhaled breath was collected from a subject who had been fasting for $2 \mathrm{~h}$ before the 
experiment and had administered no alcohol and medicine for three days prior to the experiment. The exhaled breath was sampled through the end-expiratory sampling. A subject drew in a deep breath though the nose and stopped for $10 \mathrm{~s}$. Then, the subject breathed out through a mouth gently for $3 \mathrm{~s}$ to discard the dead space, followed by exhaling into a gas sampling bag. In the breath measurement, we pumped the breath sample to the $\mathrm{MeOH}$ bio-sniffer at the flow rate of $200 \mathrm{~mL} / \mathrm{min}$ using a diaphragm pump (DSA-2-12, Denso Sangyo, Tokyo, Japan).

\section{Results and Discussion}

\subsection{Optimization of AOD-FALDH Membrane}

First, FALDH from different manufacturers were compared by the AOD-FALDH fluorosensor. The details of the AOD-FALDH fluorescence was described in the previous study [36]. Briefly, the AOD-FALDH membrane was attached at the end of the optical fiber probe that was connected to a bifurcated optical fiber (BIF600-UV/VIS, Ocean Optics, USA). Two ends of the bifurcated fiber were connected to the same UV-LED and PMT with the $\mathrm{MeOH}$ bio-sniffer. The fiber probe with the AOD-FALDH membrane was immersed in $\mathrm{NAD}^{+}$solution $(20 \mathrm{mM}$ in $\mathrm{pH} 8.5 \mathrm{~PB}$ ) to excite $\mathrm{NADH}$ that was produced from the cascade reaction of $\mathrm{MeOH}$ with AOD and FALDH. Please note that the AOD-FALDH membrane used in this liquid phase fluorosensor had no waterproof treatment.

Figure 3a shows a comparison of the sensor output of the AOD-FALDH fluorosensor to $1 \mathrm{mM} \mathrm{MeOH}$ or ethanol solution. For the AOD-FALDH membrane using FALDH from Funakoshi, the relative sensor output to ethanol solution was about 3 times lower than that from Toyobo, indicating that higher selectivity to $\mathrm{MeOH}$ can be obtained using FALDH from Funakoshi. This difference may be attributed to variations of bacteria and manufacturing conditions between two manufacturers. Although both FALDH were from Pseudomonas species, at present, there are more than 180 validly named species of Pseudomonas [45]. Therefore, it is supposed that activity and specificity of enzymes from different manufacturers are different. Based on this result, we decided to use FALDH from Funakoshi to prepare the membrane in subsequent experiments.

(a)

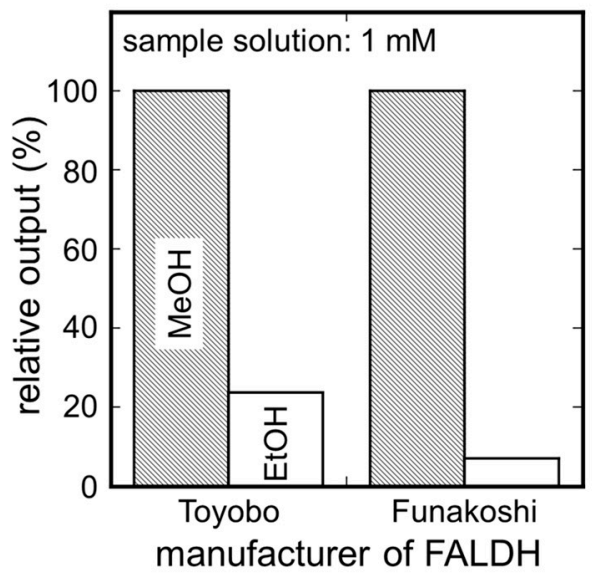

(b)

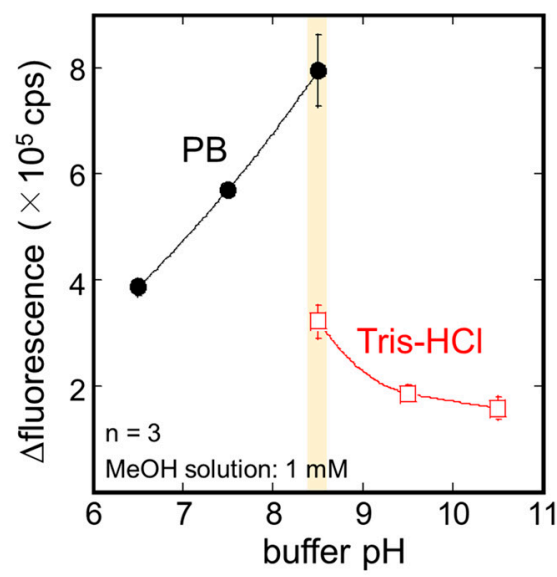

Figure 3. (a) Comparison of sensor output to $\mathrm{MeOH}$ and ethanol solutions using two different FALDH. (b) Influences of buffer solution $\mathrm{pH}$ on the activity of the AOD-FALDH membrane. Both if the experiments were carried out by the AOD-FALDH fluorosensor in the liquid phase.

Next, the optimum $\mathrm{pH}$ for the AOD-FALDH membrane was investigated using the AOD-FALDH fluorosensor. The $\mathrm{pH}$ of the buffer solutions containing $\mathrm{NAD}^{+}$was changed from 6.5 to 10.5 using $\mathrm{PB}$ and Tris- $\mathrm{HCl}$ (Figure 3b). $\mathrm{MeOH}$ solution was dropped into the buffer solution to make $1 \mathrm{mM} \mathrm{MeOH}$ solution while the probe of the AOD-FALDH fluorosensor was immersed in the buffer solution. As a result of three trials, the fluorescence output from $1 \mathrm{mM} \mathrm{MeOH}$ solution increased with increasing $\mathrm{pH}$ and became the maximum 
with $\mathrm{pH}$ 8.5 PB solution. Although the fluorescence output from Tris- $\mathrm{HCl}$ solution at $\mathrm{pH}$ 8.5 was lower than that with $\mathrm{PB}$, it showed the maximum at $\mathrm{pH} 8.5$ and decreased with increasing $\mathrm{pH}$. These results indicated that using $\mathrm{PB}$ solution at $\mathrm{pH} 8.5$ would allow for maximizing the catalytic activity of the AOD-FALDH membrane, and therefore, we decided to use $\mathrm{pH}$ 8.5 PB solution in subsequent experiments.

The influences of waterproof materials on the AOD-FALDH membrane were investigated. Except for the membrane coated with fluorine resin, no water leakage occurred. Figure 4 shows sensor responses to $4.8 \mathrm{ppm} \mathrm{MeOH}$ vapor by the $\mathrm{MeOH}$ bio-sniffer using differently waterproofed AOD-FALD membranes. All types of membranes resulted in the increase in the fluorescence from $\mathrm{NADH}$ upon applying $\mathrm{MeOH}$ vapor. Among them, the membrane waterproofed by spin-coating PMEH showed the largest sensor output along with a superior response represented by the time to reach $90 \%$ of the stable value $\left(T_{90}\right)$. The membrane prepared by spin-coated PMEH exhibited $T_{90}$ of $91 \mathrm{sec}$, which was more than twice better than the others: casted PMEH, $229 \mathrm{sec}$; fluorine resin, $295 \mathrm{sec}$; silicone resin, $195 \mathrm{sec}$. Based on the all abovementioned aspects, we decided to waterproof the gas-phase side of the AOD-FALDH membrane by spin-coating PMEH.

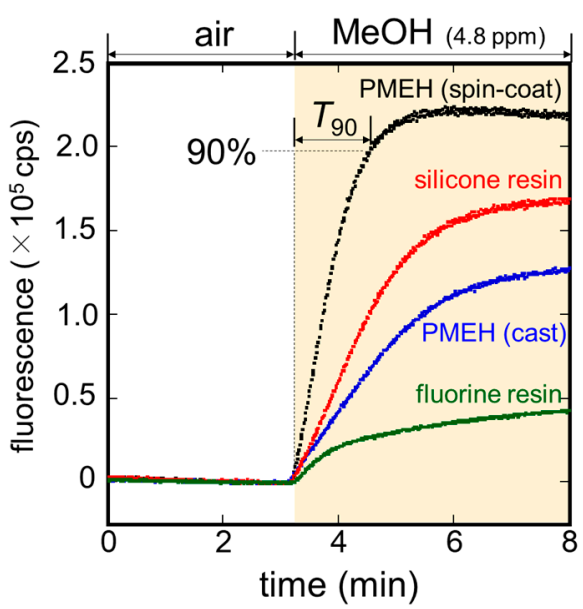

Figure 4. Sensor responses to $4.8 \mathrm{ppm} \mathrm{MeOH}$ vapor from the $\mathrm{MeOH}$ bio-sniffer, which employed four different waterproof treatments (spin-coating $\mathrm{PMEH}$, casting $\mathrm{PMEH}$, and spraying silicone or fluorine resins) on the gas-phase side of the AOD-FALDH membrane.

\subsection{Sensitivity to $\mathrm{MeOH}$ Vapor}

The sensitivity of the $\mathrm{MeOH}$ bio-sniffer to $\mathrm{MeOH}$ vapor was investigated. The sensorgrams of the bio-sniffer to various concentrations of $\mathrm{MeOH}$ vapor are shown in Figure 5a. Following the stable baseline in air, the fluorescence intensity increased as a response to $\mathrm{MeOH}$ vapor. The increment in the fluorescence intensity was different depending on the concentration of $\mathrm{MeOH}$ vapor, suggesting the sensor output and the $\mathrm{MeOH}$ vapor concentration have a correlation. After demonstrating the measurement three times for each concentration, we summarized the sensor output, which was obtained by averaging fluorescence intensity for the last $30 \mathrm{~s}$ of the $\mathrm{MeOH}$ vapor application, as a function of the concentration of $\mathrm{MeOH}$ vapor in Figure 5b. A fitting curve of the plot was made by the following equation:

$$
\Delta F I(\mathrm{cps})=A[\mathrm{MeOH} \text { vapor }(\mathrm{ppm})])^{B}
$$

where $A=1.23 \times 10^{4}$ and $B=1.02$ are the coefficients with a correlation coefficient $R$ of 0.991; [ $\mathrm{MeOH}$ vapor] is the concentration of $\mathrm{MeOH}$ vapor in ppm. This calibration curve allowed us to determine the dynamic range of the $\mathrm{MeOH}$ bio-sniffer as $0.32-20 \mathrm{ppm}$. Here, the limit of quantification (LOQ) was calculated from ten times the standard deviation of the sensor baseline signal and Equation (1). The obtained dynamic range was found to encompass $\mathrm{MeOH}$ concentration in exhaled breath (0.10-2.3 ppm) [46], and therefore, the measurement of $\mathrm{MeOH}$ in exhaled breath by the $\mathrm{MeOH}$ bio-sniffer was highly possible. 
(a)

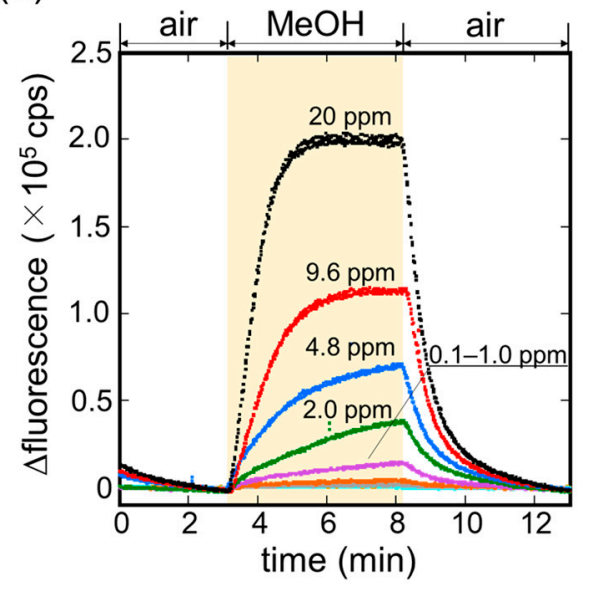

(b)

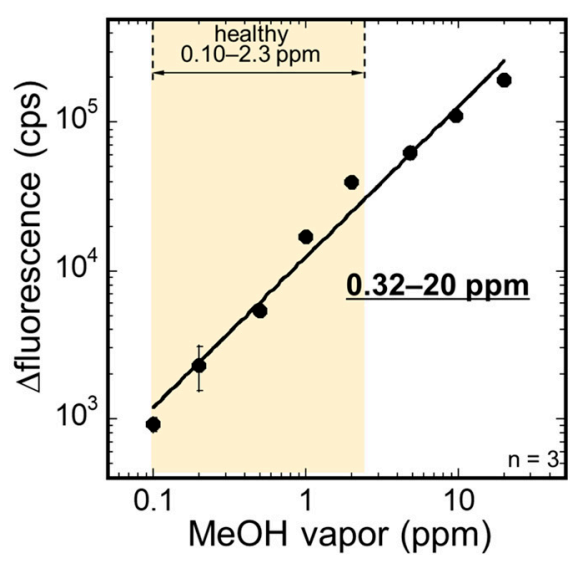

Figure 5. (a) Sensor outputs to various concentrations of $\mathrm{MeOH}$ vapor. (b) A calibration curve of the bio-sniffer to $\mathrm{MeOH}$ vapor.

A characteristics comparison of the $\mathrm{MeOH}$ bio-sniffer with various reported sensors is shown in Table 1. It shows the high sensitivity of the bio-sniffer among the state-of-the-art $\mathrm{MeOH}$ gas sensors.

Table 1. Comparison of the proposed MeOH bio-sniffer with various reported sensors.

\begin{tabular}{|c|c|c|c|c|}
\hline Technology & Material & Dynamic Range & Operating Temp. & Ref. \\
\hline Chemoresistive & $\begin{array}{c}\mathrm{Pd}-\mathrm{SnO}_{2} \\
\text { nanoparticles }\end{array}$ & 1-1000 ppm & $350^{\circ} \mathrm{C}$ & [33] \\
\hline $\begin{array}{c}\text { Substrate } \\
\text { integrated } \\
\text { waveguide }\end{array}$ & Polyindole & 5-500 ppm & RT & [47] \\
\hline Split ring resonator & $\begin{array}{l}\text { Carbon nanotube } \\
\text { coated carbon fiber }\end{array}$ & 10-300 ppm & RT & [48] \\
\hline Chemoresistive & $\begin{array}{c}\text { Ce-doped } \mathrm{In}_{2} \mathrm{O}_{3} \\
\text { porous nanospheres }\end{array}$ & 2-1000 ppm & $320^{\circ} \mathrm{C}$ & [49] \\
\hline Amperometric & $\begin{array}{l}\text { Platinum decorated } \\
\text { mesoporous TiN }\end{array}$ & 10-300 ppm & RT & [50] \\
\hline Biofluorescence & AOD-FALDH & $0.32-20 \mathrm{ppm}$ & RT & This work \\
\hline
\end{tabular}

\subsection{Measurement of $\mathrm{MeOH}$ in Exhaled Breath}

The measurement of $\mathrm{MeOH}$ in exhaled breath of a healthy subject was carried out using the $\mathrm{MeOH}$ bio-sniffer. The sensorgram during the measurement is presented in Figure 6. The observed sensorgram to the exhaled breath was similar to that of the standard $\mathrm{MeOH}$ vapor (see Figure 5a). The fluorescence intensity increased upon pumping the breath sample to the bio-sniffer; then it returned to the baseline when changing breath sample to the filtered air. The concentration of $\mathrm{MeOH}$ in the exhaled breath sample was calculated from the average fluorescence intensity of the last $30 \mathrm{~s}$ of the breath sample application and equation 1 , and it was of $0.78 \mathrm{ppm}$. The consistency of this value with the concentration range reported by other studies $(0.10-2.3 \mathrm{ppm})$ [46] supported the validity of the measurement. 


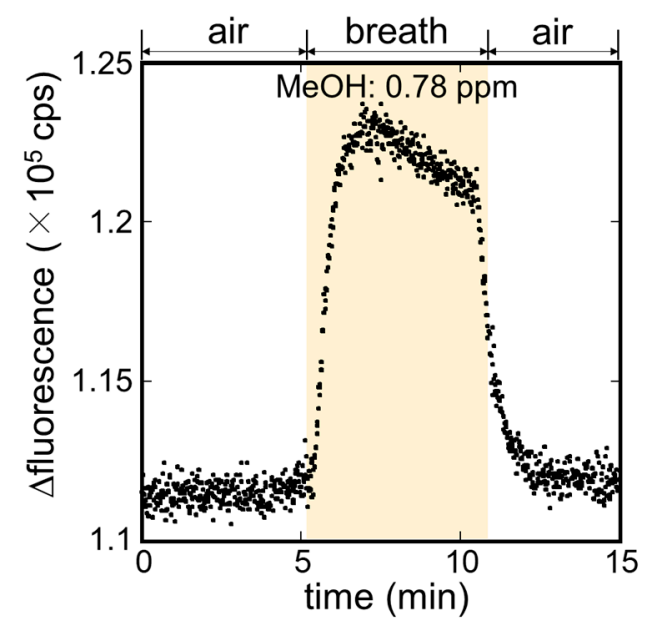

Figure 6. Sensor response to exhaled breath from a healthy subject.

According to our previous study regarding the AOD-FALDH fluorosensor, the cascade reaction with AOD and FALDH allowed for selective discrimination of methanol from other aliphatic alcohols including ethanol, 1-propanol, 1-butanol, and 2-propanol [36]. On the other hand, it was also observed that use of FALDH lead to reaction with aldehydes such as acetaldehyde and formaldehyde. However, according to the reports by Čáp et al., concentrations of those aldehydes in healthy subject's breath (acetaldehyde: $7 \mathrm{ppb}$; formaldehyde: $1 \mathrm{ppb}$ ) are much lower than that of $\mathrm{MeOH}(189 \mathrm{ppb})$ [46]. Therefore, we have concluded that the signal observed in this experiment was derived from $\mathrm{MeOH}$.

\section{Conclusions}

In this study, we have developed a biochemical gas sensor (bio-sniffer) for $\mathrm{MeOH}$ using a cascade reaction with AOD and FALDH for the non-invasive assessment of intestinal flora. After a series of optimizations including FALDH, $\mathrm{pH}$ of buffer solution, and methods to prevent water leak from the AOD-FALDH membrane, the dynamic range of the $\mathrm{MeOH}$ bio-sniffer was found to be $0.32-20 \mathrm{ppm}$. This high sensitivity along with the known superior selectivity to $\mathrm{MeOH}$ with the cascade reaction suggested the possibility of breath $\mathrm{MeOH}$ measurement. In the measurement of exhaled breath sample from a healthy subject, a sensorgram similar to that with standard $\mathrm{MeOH}$ vapor was observed. The calculated $\mathrm{MeOH}$ concentration in the exhaled breath was $0.78 \mathrm{ppm}$. The consistency of this value to the reported concentration supported the validity of the measurement and the capability of the $\mathrm{MeOH}$ bio-sniffer. The characterizations and a preliminary demonstration with exhaled $\mathrm{MeOH}$ in this study indicate the utility and feasibility of the bio-sniffer in the breath $\mathrm{MeOH}$ measurement. In future study, we will perform deeper statistical analysis by increasing the number of subjects and investigate the correlation of exhaled methanol and intestinal flora status using the $\mathrm{MeOH}$ bio-sniffer to explore the possibility of non-invasive assessment of intestinal flora by exhaled $\mathrm{MeOH}$.

Author Contributions: Conceptualization, K.T., K.I. (Kenta Iitani), T.A. and K.M.; methodology, K.I. (Kanako Iwasaki), G.Z. and Y.I.; validation, K.T., K.I. (Kanako Iwasaki), G.Z. and K.I. (Kenta Iitani); investigation, K.I. (Kanako Iwasaki); T.A., Y.I. and K.M.; data curation, K.I. (Kanako Iwasaki), G.Z.; writing—original draft preparation, K.T. and K.I. (Kanako Iwasaki); visualization, K.T. and K.I. (Kanako Iwasaki); supervision, K.T., K.I. (Kenta Iitani), T.A. and K.M.; project administration, K.T., K.I. (Kenta Iitani), T.A. and K.M.; funding acquisition, T.A. and K.M. All authors have read and agreed to the published version of the manuscript.

Funding: This work was partly supported by Japan Society for the Promotion of Science (JSPS, Japan) KAKENHI Grant Number JP 17H01759, 16KK0143 and 15H04013; a grant from Japan IDDM network; the Ministry of Education, Culture, Sports, Science and Technology (MEXT, Japan) Special Funds for "Cooperative Research Project of Research Center for Biomedical Engineering". 
Institutional Review Board Statement: The study was conducted according to the guidelines of the Declaration of Helsinki, and approved by the Ethics Committee of Institute of Biomaterials and Bioengineering, Tokyo Medical and Dental University (approval number: B2014-001).

Informed Consent Statement: Informed consent was obtained from all subjects involved in the study.

Conflicts of Interest: The authors declare no conflict of interest.

\section{References}

1. Larsen, N.; Vogensen, F.K.; Van Den Berg, F.W.J.; Nielsen, D.S.; Andreasen, A.S.; Pedersen, B.K.; Al-Soud, W.A.; Sørensen, S.J.; Hansen, L.H.; Jakobsen, M. Gut microbiota in human adults with type 2 diabetes differs from non-diabetic adults. PLoS ONE 2010, 5, e9085. [CrossRef] [PubMed]

2. Ravcheev, D.A.; Godzik, A.; Osterman, A.L.; Rodionov, D.A. Polysaccharides utilization in human gut bacterium Bacteroides thetaiotaomicron: Comparative genomics reconstruction of metabolic and regulatory networks. BMC Genom. 2013, 14, 1-17. [CrossRef] [PubMed]

3. Ley, R.E.; Peterson, D.A.; Gordon, J.I. Ecological and Evolutionary Forces Shaping Microbial Diversity in the Human Intestine. Cell 2006, 124, 837-848. [CrossRef]

4. Savage, D.C. Microbial Ecology of the Gastrointestinal Tract. Annu. Rev. Microbiol. 1977, 31, 107-133. [CrossRef] [PubMed]

5. Whitman, W.B.; Coleman, D.C.; Wiebe, W.J. Prokaryotes: The unseen majority. Proc. Natl. Acad. Sci. USA 1998, 95, 6578-6583. [CrossRef]

6. Sekirov, I.; Russell, S.L.; Antunes, L.C.M.; Finlay, B.B. Gut Microbiota in Health and Disease Gut Microbiota in Health and Disease. Physiol. Rev. 2016, 859-904. [CrossRef]

7. Hooper, L.V.; Stappenbeck, T.S.; Hong, C.V.; Gordon, J.I. Angiogenins: A new class of microbicidal proteins involved in innate immunity. Nat. Immunol. 2003, 4, 269-273. [CrossRef] [PubMed]

8. Achilefu, A.; Joshi, K.; Meier, M.; Mccarthy, L.H.; Medicine, F.; Program, R.; City, O. The influence of gut microbiota on drug metabolism and toxicity. Expert Opin. Drug Metab. Toxicol. 2017, 110, 14-16. [CrossRef]

9. Turnbaugh, P.J.; Ley, R.E.; Mahowald, M.A.; Magrini, V.; Mardis, E.R.; Gordon, J.I. An obesity-associated gut microbiome with increased capacity for energy harvest. Nature 2006, 444, 1027-1031. [CrossRef]

10. Drasar, B.S. Cultivation of anaerobic intestinal bacteria. Pathology 1967, 94, 417-427. [CrossRef]

11. Mata, L.J.; Carrillo, C.; Villatoro, E. Fecal Microflora in Healthy Persons in a Preindustrial Region. Appl. Microbiol. 1969, 17, 596-602. [CrossRef] [PubMed]

12. Ignyś, I.; Szachta, P.; Gałęcka, M.; Schmidt, M.; Pazgrat-Patan, M.; Pazgrat-Patan, M. Methods of analysis of gut microorganismActual state of knowledge. Ann. Agric. Environ. Med. 2014, 21, 799-803. [CrossRef]

13. Bäckhed, F.; Ley, R.E.; Sonnenburg, J.L.; Peterson, D.A.; Gordon, J.I. Host-bacterial mutualism in the human intestine. Science 2005, 307, 1915-1920. [CrossRef]

14. Abubucker, S.; Segata, N.; Goll, J.; Schubert, A.M.; Izard, J.; Cantarel, B.L.; Rodriguez-Mueller, B.; Zucker, J.; Thiagarajan, M.; Henrissat, B.; et al. Metabolic reconstruction for metagenomic data and its application to the human microbiome. PLoS Comput. Biol. 2012, 8. [CrossRef]

15. Dorokhov, Y.L.; Shindyapina, A.V.; Sheshukova, E.V.; Komarova, T.V. Metabolic Methanol: Molecular Pathways and Physiological Roles. Physiol. Rev. 2015, 95, 603-644. [CrossRef] [PubMed]

16. Martens, E.C.; Lowe, E.C.; Chiang, H.; Pudlo, N.A.; Wu, M.; McNulty, N.P.; Abbott, D.W.; Henrissat, B.; Gilbert, H.J.; Bolam, D.N.; et al. Recognition and degradation of plant cell wall polysaccharides by two human gut symbionts. PLoS Biol. 2011, 9. [CrossRef]

17. Siragusa, R.J.; Cerda, J.J.; Baig, M.M.; Burgin, C.W.; Robbins, F.L. Methanol production from the degradation of pectin by human colonic bacteria. Am. J. Clin. Nutr. 1988, 47, 848-851. [CrossRef] [PubMed]

18. Laakso, O.; Haapala, M.; Jaakkola, P.; Laaksonen, R.; Luomanmäki, K.; Nieminen, J.; Pettersson, M.; Päivä, H.; Räsänen, M.; Himberg, J.J. FT-IR breath test in the diagnosis and control of treatment of methanol intoxications. J. Anal. Toxicol. 2001, 25, 26-30. [CrossRef]

19. Dorokhov, Y.L.; Komarova, T.V.; Petrunia, I.V.; Kosorukov, V.S.; Zinovkin, R.A.; Shindyapina, A.V.; Frolova, O.Y.; Gleba, Y.Y. Methanol may function as a Cross-Kingdom signal. PLoS ONE 2012, 7, e36122. [CrossRef] [PubMed]

20. Lindinger, W.; Taucher, J.; Jordan, A.; Hansel, A.; Vogel, W. Endogenous production of methanol after the consumption of fruit. Alcohol. Clin. Exp. Res. 1997, 21, 939-943. [CrossRef]

21. Eriksen, S.P.; Kulkarni, A.B. Methanol in normal human breath. Science 1963, 141, 639-640. [CrossRef]

22. Turner, C.; Španěl, P.; Smith, D. A longitudinal study of methanol in the exhaled breath of 30 healthy volunteers using selected ion flow tube mass spectrometry, SIFT-MS. Physiol. Meas. 2006, 27, 637-648. [CrossRef]

23. Španěl, P.; Dryahina, K.; Vicherková, P.; Smith, D. Increase of methanol in exhaled breath quantified by SIFT-MS following aspartame ingestion. J. Breath Res. 2015, 9, 047104. [CrossRef] [PubMed]

24. He, C.; Liu, L.; Korposh, S.; Correia, R.; Morgan, S.P. Volatile Organic Compound Vapour Measurements Using a Localised Surface Plasmon Resonance Optical Fibre Sensor Decorated with a Metal-Organic Framework. Sensors 2021, 21, 1420. [CrossRef] [PubMed] 
25. Kittle, J.; Fisher, B.; Kunselman, C.; Morey, A.; Abel, A. Vapor Selectivity of a Natural Photonic Crystal to Binary and Tertiary Mixtures Containing Chemical Warfare Agent Simulants. Sensors 2019, 20, 157. [CrossRef] [PubMed]

26. Furuuchi, N.; Shrestha, R.; Yamashita, Y.; Hirao, T.; Ariga, K.; Shrestha, L. Self-Assembled Fullerene Crystals as Excellent Aromatic Vapor Sensors. Sensors 2019, 19, 267. [CrossRef] [PubMed]

27. Slobodian, P.; Riha, P.; Olejnik, R.; Matyas, J.; Slobodian, R. Microstrip Resonant Sensor for Differentiation of Components in Vapor Mixtures. Sensors 2021, 21, 298. [CrossRef] [PubMed]

28. Blank, A.; Guendelman, G.; Linzon, Y. Vapor Sensing with Polymer Coated Straight Optical Fiber Microtapers Based on Index Sensitive Interference Spectroscopy of Surface Stress Birefringence. Sensors 2020, 20, 2675. [CrossRef]

29. Angulo Barrios, C. Scotch Tape Optical Vapor Sensor for Ethanol-Methanol Mixtures. Sensors 2019, 19, 5381. [CrossRef]

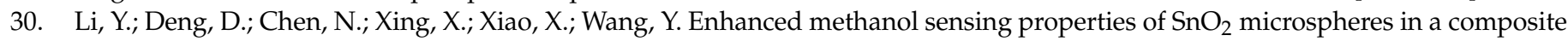
with Pt nanoparticles. RSC Adv. 2016, 6, 83870-83879. [CrossRef]

31. Chen, Y.; Dong, Z.; Xue, X.; Chen, S.; Natan, A.; Lv, Y.; Chen, C.; Yang, Y.Y.; Cen, W.; Yang, Y.Y. High-sensitivity and high-selectivity detection of methanol based on La-doped $\mathrm{SnO}_{2}$ sensor. Appl. Phys. A Mater. Sci. Process. 2020, 126. [CrossRef]

32. Andrés, M.A.; Vijjapu, M.T.; Surya, S.G.; Shekhah, O.; Salama, K.N.; Serre, C.; Eddaoudi, M.; Roubeau, O.; Gascón, I. Methanol and Humidity Capacitive Sensors Based on Thin Films of MOF Nanoparticles. ACS Appl. Mater. Interfaces 2020, 12, 4155-4162. [CrossRef]

33. van den Broek, J.; Abegg, S.; Pratsinis, S.E.; Güntner, A.T. Highly selective detection of methanol over ethanol by a handheld gas sensor. Nat. Commun. 2019, 10, 1-8. [CrossRef] [PubMed]

34. Güntner, A.T.; Magro, L.; van den Broek, J.; Pratsinis, S.E. Detecting methanol in hand sanitizers. iScience 2021, $24,102050$. [CrossRef]

35. Hayasaka, T.; Lin, A.; Copa, V.C.; Lopez, L.P.; Loberternos, R.A.; Ballesteros, L.I.M.; Kubota, Y.; Liu, Y.; Salvador, A.A.; Lin, L. An electronic nose using a single graphene FET and machine learning for water, methanol, and ethanol. Microsyst. Nanoeng. 2020, 6. [CrossRef]

36. Toma, K.; Iwasaki, K.; Arakawa, T.; Iwasaki, Y.; Mitsubayashi, K. Sensitive and selective methanol biosensor using two-enzyme cascade reaction and fluorometry for non-invasive assessment of intestinal bacteria activity. Biosens. Bioelectron. 2021, 181, 113136. [CrossRef] [PubMed]

37. Mansour, E.; Vishinkin, R.; Rihet, S.; Saliba, W.; Fish, F.; Sarfati, P.; Haick, H. Measurement of temperature and relative humidity in exhaled breath. Sens. Actuators B Chem. 2020, 304, 127371. [CrossRef]

38. Chien, P.-J.; Suzuki, T.; Tsujii, M.; Ye, M.; Toma, K.; Arakawa, T.; Iwasaki, Y.; Mitsubayashi, K. Bio-sniffer (gas-phase biosensor) with secondary alcohol dehydrogenase (S-ADH) for determination of isopropanol in exhaled air as a potential volatile biomarker. Biosens. Bioelectron. 2017, 91, 341-346. [CrossRef] [PubMed]

39. Iitani, K.; Chien, P.-J.; Suzuki, T.; Toma, K.; Arakawa, T.; Iwasaki, Y.; Mitsubayashi, K. Fiber-Optic Bio-sniffer (Biochemical Gas Sensor) Using Reverse Reaction of Alcohol Dehydrogenase for Exhaled Acetaldehyde. ACS Sens. 2018, 3, 425-431. [CrossRef]

40. Chien, P.-J.J.; Suzuki, T.; Tsujii, M.; Ye, M.; Minami, I.; Toda, K.; Otsuka, H.; Toma, K.; Arakawa, T.; Araki, K.; et al. Biochemical Gas Sensors (Biosniffers) Using Forward and Reverse Reactions of Secondary Alcohol Dehydrogenase for Breath Isopropanol and Acetone as Potential Volatile Biomarkers of Diabetes Mellitus. Anal. Chem. 2017, 89, 12261-12268. [CrossRef] [PubMed]

41. Toma, K.; Suzuki, S.; Arakawa, T.; Iwasaki, Y.; Mitsubayashi, K. External ears for non-invasive and stable monitoring of volatile organic compounds in human blood. Sci. Rep. 2021, 11, 10415. [CrossRef]

42. Kudo, H.; Yagi, T.; Chu, M.X.; Saito, H.; Morimoto, N.; Iwasaki, Y.; Akiyoshi, K.; Mitsubayashi, K. Glucose sensor using a phospholipid polymer-based enzyme immobilization method. Anal. Bioanal. Chem. 2008, 391, 1269-1274. [CrossRef]

43. Toma, K.; Tsujii, M.; Arakawa, T.; Iwasaki, Y.; Mitsubayashi, K. Dual-target gas-phase biosensor (bio-sniffer) for assessment of lipid metabolism from breath acetone and isopropanol. Sens. Actuators B Chem. 2021, 329, 129260. [CrossRef]

44. Arakawa, T.; Suzuki, T.; Tsujii, M.; Iitani, K.; Chien, P.-J.J.; Ye, M.; Toma, K.; Iwasaki, Y.; Mitsubayashi, K. Real-time monitoring of skin ethanol gas by a high-sensitivity gas phase biosensor (bio-sniffer) for the non-invasive evaluation of volatile blood compounds. Biosens. Bioelectron. 2019, 129, 245-253. [CrossRef] [PubMed]

45. Hesse, C.; Schulz, F.; Bull, C.T.; Shaffer, B.T.; Yan, Q.; Shapiro, N.; Hassan, K.A.; Varghese, N.; Elbourne, L.D.H.; Paulsen, I.T.; et al. Genome-based evolutionary history of Pseudomonas spp. Environ. Microbiol. 2018, 20, 2142-2159. [CrossRef] [PubMed]

46. Čáp, P.; Dryahina, K.; Pehal, F.; Španěl, P. Selected ion flow tube mass spectrometry of exhaled breath condensate headspace. Rapid Commun. Mass Spectrom. 2008, 22, 2844-2850. [CrossRef]

47. Kumar, A.; Wang, C.; Meng, F.Y.; Jiang, C.P.; Yan, G.F.; Zhao, M.; Jing, C.Q.; Wang, L. Ultrafast Detection and Discrimination of Methanol Gas Using a Polyindole-Embedded Substrate Integrated Waveguide Microwave Sensor. ACS Sens. 2020, 5, 3939-3948. [CrossRef] [PubMed]

48. Singh, S.K.; Azad, P.; Akhtar, M.J.; Kar, K.K. Improved Methanol Detection Using Carbon Nanotube-Coated Carbon Fibers Integrated with a Split-Ring Resonator-Based Microwave Sensor. ACS Appl. Nano Mater. 2018, 1, 4746-4755. [CrossRef]

49. Han, D.; Song, P.; Zhang, S.; Zhang, H.; Xu, Q.; Wang, Q. Enhanced methanol gas-sensing performance of Ce-doped In2O3 porous nanospheres prepared by hydrothermal method. Sens. Actuators B Chem. 2015, 216, 488-496. [CrossRef]

50. Meng, D.; Zhang, S.; Thomas, T.; Zhao, R.; Shi, Y.; Qu, F.; Yang, M. Platinum decorated mesoporous titanium nitride for fuel-cell type methanol gas sensor. Sens. Actuators B Chem. 2020, 308, 127713. [CrossRef] 